www.jmscr.igmpublication.org

Impact Factor 5.244

Index Copernicus Value: 83.27

ISSN (e)-2347-176x ISSN (p) 2455-0450

crossref DOI:_http://dx.doi.org/10.18535/jmscr/v4i7.51

Journal Of Medical Science And Clinical Research

\title{
Cardiac Auscultation Versus Two-dimensional Trans thoracic Echocardiography in Native Aortic and Mitral Valve diseases in Erbil City
}

Authors

\author{
Aree Nadhem A.Daham ${ }^{1}$, Mohammed Hasan Al-Meshhadani ${ }^{2}$
}

${ }^{1}$ M.B.Ch.B, Higher Diploma Medicine, Ministry of health/ Iraq

Email:aree_daham@yahoo.com,009647504536720

${ }^{2}$ M.B.Ch.B-D.M.-F.I.C.M.S, (Med) - F.I.C.M.S (Cardiol), Hawler medical university- Medical College/Iraq Email:mohdcrt@yahoo.com,009647504272850

\begin{abstract}
Background: Echocardiography is use for diagnosis and assessment of valvular heart disease as there are many valve diseases that are silent on clinical auscultation.

Objective: To identify the sensitivity of auscultation in patients with mitral and aortic valve diseases in comparison with Doppler echocardiography.

Materials and methods: An observational study was done on 950 patients were attended echocardiography department of Erbil cardiac center between May 2015 and February 2016, only 300 patients fulfils the criteria of the study were included in the study. Patients from the age of 15 years and above were randomly selected. Cardiac auscultation of mitral and aortic precordial areas was done by 2 experience cardiologists. Then patients were examined thoroughly by transthoracic echocardiography for underlying valve lesion.

Results: From total 189 MR lesions detected by echocardiography in 94 (49.7\%) lesions no murmur was detected, from $36 \mathrm{MS}$ lesions in 12 (33.3\%) lesions no murmur was detected, from 86 AR lesions in 50 (58.1\%) lesions and from total 40 AS lesions in $5(12.5 \%)$ lesions the murmur were not detected clinically with a significant $P$ value $(p$ value $=0.001),(p$ value $=0.001),(p$ value $=0.001),(p$ value $=0.001)$ respectively. Significant association of inaudible murmurs with mild valve lesions on echocardiography ( $p$ value $=0.001$ ) and with echocardiographic systolic dysfunction ( $p$ value $=0.001$ ). Sensitivity of auscultation in mitral and aortic valve diseases was $55.7 \%$ and $48.4 \%$ respectively.

Conclusions: Many valve diseases which were diagnosed by echocardiography could be silent clinically

Keywords: Auscultation, Aortic valve, mitral valve, echocardiography.
\end{abstract}

\section{Introduction}

Valvular heart disease accounts for $10 \%$ to $20 \%$ of all cardiac surgical procedures in the United States. Approximately two thirds of all heart valve operations are for aortic valve replacement (AVR), most often for aortic stenosis (AS). Mitral valve surgery most often is performed for mitral regurgitation (MR); most patients with mitral stenosis (MS) are treated by a percutaneous approach. There is a larger group of patients with mild to moderate disease who need accurate diagnosis and appropriate medical management. ${ }^{1}$ Approximately $25 \%$ of all patients with rheumatic heart disease have pure MS, and an additional 40\% have combined MS and mitral regurgitation $(\mathrm{MR})^{2}$. Aortic stenosis is said to be severe if the 
valve area is less than $1.0 \mathrm{~cm} 2$, mean gradient greater than $40 \mathrm{~mm} \mathrm{Hg}$, or jet velocity greater than $4.0 \mathrm{~m} / \mathrm{s}^{3}$. A louder and later-peaking murmur indicates more severe stenosis. However, although a systolic murmur of grade 3 intensity or greater is relatively specific for severe AS, this finding is insensitive. Aortic regurgitation, like other valve abnormalities, often produces no symptoms for many years ${ }^{4}$. A congenital bicuspid aortic valve is present in approximately $1 \%$ to $2 \%$ of the population and is more prevalent in $\mathrm{men}^{5}$. A murmur is a sound generated when blood travels through vessels or valves in a turbulent or energydissipating manner. It can be an important clue to a structural abnormality of the cardiovascular system. In valvular and congenital forms of heart disease, a murmur is usually the major evidence of the abnormality, although some hemodynamically significant regurgitant lesions may be silent. However, many murmurs in asymptomatic people are innocent and of no functional significance ${ }^{6}$. In the evaluation of heart murmurs, the purposes of performing a Doppler echocardiogram are to define the primary lesion and its etiology and judge its severity, define hemodynamics, detect coexisting abnormalities, detect lesions secondary to the primary lesion, evaluate cardiac size and function, establish a reference point for future observations, reevaluate the patient after an intervention. As valuable as echocardiography may be, the basic cardiovascular evaluation is still the most appropriate method to screen for cardiac disease and will establish many clinical diagnoses 7 . Cardiac auscultation remains the most widely used method of screening for heart disease, despite the current emphasis on technology, the cardiac stethoscopic examination, when performed properly, remains a valuable and cost-effective clinical skill that often establishes the diagnosis, etiology, and severity of heart disease. The bell, when applied gently to the skin, will "bring out" low-frequency sound and murmurs (eg S4 or S3 gallops, diastolic rumble of mitral stenosis). The diaphragm, when pressed firmly against the chest wall, will accentuate high-pitched auscultatory events (e.g, diastolic murmur of aortic regurgitation, pericardial friction rub) ${ }^{8}$. Intensity is synonymous with the loudness or amplitude of a sound wave, and it is inversely related to the size of the opening or vessel that blood travels through, and directly proportional to the pressure gradient and the amount of blood flow through that opening ${ }^{9-10}$.

\section{Materials and methods}

Setting: the study was carried out in Surgical Specialty Hospital- cardiac center in Erbil city.

Design: An observational descriptive study was done on 950 patients were attended echocardiography department of Erbil cardiac center for echocardiography examination between May 2015 and February 2016, but only 300 patients whom fulfils the criteria of the study were included. Both male and female from the age of 15 years and above, and all of these cases were randomly selected. Exclusion criterias including age less than 15 years old, poor window echocardiography, prosthetic aortic and mitral valves, history of infective endocarditis, pregnancy, and congenital heart diseases.

Data collections: After an informed consent about the plan and objectives of the study was discussed with the patients, the data was collected by designing appropriate questionnaire including information about socio-demographic data (name, age, sex, occupation), a detailed history was taken from the patients including previous history of cardiac disease, previous history of cardiac surgery, cardiac risk factors such as smoking, diabetes mellitus and hypertension. A detailed cardiac auscultation was done by 2 experience cardiologists. Mitral (left $5^{\text {th }}$ intercostal space mid clavicular line) and traditional areas of auscultation Sounds and murmurs of the aortic valve and aorta were examined at the second right intercostal space and the mid left sternal border, using a stethoscope Littman 3M class made in USA. Murmur radiation to neck, systolic ejection murmur of aortic stenosis (AS), Left axilla 
radiation of mitral regurgitation (MR) ${ }^{8-10}$. Murmur of aortic regurgitation (Early diastolic) and aortic stenosis (Ejection systolic) during expiration were concentrated on and classifying the murmurs in to low (using valsalva or hand grip maneuver if needed), moderate and high intensity murmurs along with murmur radiation ${ }^{1}$. The aortic regurgitant murmur is of high frequency and begins immediately after A2. In mild AR, the murmur limited to early diastole and typically is high-pitched and blowing. In severe AR, the murmur is holodiastolic and may have a rough quality $^{1,11}$. After auscultation, patients were examined thoroughly by transthoracic echocardiography using VIVID E9 ultrasonic machine made in USA for the detection of any structural cardiac abnormalities including mitral and aortic valve diseases, chambers dimensions, systolic function by M-Mode and the estimation of the diastolic pressure gradient which is derived from the transmitral velocity flow by the use of CWD. Echocardiographic demonstration of mitral valve stenosis including mitral valve area planimetry which was considered as the reference measurement of mitral valve area. Mitral valve area is derived using the empirical formula MVA $=220 / \mathrm{T} 1 / 2$, the severity of MS was classified as mild when MVA is more than $2 \mathrm{~cm}^{2}$, moderate when MVA is $1.5 \mathrm{~cm} 2$ to $2.0 \mathrm{~cm} 2$, severe when MVA is 1.0 to $1.5 \mathrm{~cm} 2$ and very severe if $1.0 \mathrm{~cm} 2$ or less ${ }^{12}$. Echocardiographic evidences of $\mathrm{AR}$ were includes: Mild AR when jet width $<25 \%$ of left ventricular out flow tract (LVOT), Moderate AR when jet width $25 \%-64 \%$ of LVOT, Severe AR when jet width $\geq 65 \%$ of LVOT $^{13}$.

\section{Statistical Analysis}

Data was analyzed using the Statistical Package for Social Sciences (SPSS, version 19). Chi square test of association was used to compare between proportions. When the expected count of more than $20 \%$ of the cells of the table was less than 5, Fisher's exact test was used. McNemar test was used when comparing the auscultatory results with the echo results for the same patient.

A $p$ value of $\leq 0.05$ was considered statistically significant

\section{Ethical consideration}

The participants were informed about the study objectives, and risks, and they were recruited after obtaining verbal informed consent. The proposal of this study was submitted to the College of medicine research ethics committee and was approved.

\section{Results}

The study was enrolled 950 cases including 670 male and 280 female from the age 15 to 85 years, with the mean age of $54.0 \pm 13.5$ years. Mean weight $74.5 \pm 9.7 \mathrm{~kg}$, mean height $168.4 \pm 6.0 \mathrm{~cm}$, 219 cases having diabetes mellitus and 361 cases having hypertension. From these 950 cases only 300 was fulfills the criteria for recruitment in the study which was the presence of mitral and aortic valve diseases on echocardiography examination after clinical auscultation. From clinical auscultation of cardiac mitral area of the selected 300 patients, clinical murmur was detected in 111 $(51.6 \%)$ cases, and no murmur was detected in $104(48.4 \%)$ cases neither systolic nor diastolic, on transthoracic echocardiography examination total 215 patients were found to have mitral valve diseases, either isolated or mixed valve diseases. $\mathrm{P}$ Value $<0.001$.

During auscultation from total 156 lesions of isolated MR in 85 lesions no murmur was found, among 20 lesions of isolated MS in 7 lesions the murmur was inaudible, among 16 lesions of mixed MR\&MS in 5 lesions no murmur was audible, among 6 lesions of isolated MVP in 3 lesions no click was audible, and among 17 lesions of mixed MVP\&MR in 4 lesions no systolic murmur was audible by clinical auscultation (Totally 113 valve lesions were inaudible $)(\mathrm{P}$ value $=0.001)$ as shown in table 1 . 
Table 1: The frequency of mitral valve disease with inaudible lesion on auscultation

\begin{tabular}{|l|l|l|l|}
\hline VALVE LESION & FREQUENCY No. & PERCENT \% & $\begin{array}{l}\text { CUMULATIVE } \\
\text { PERCENT \% }\end{array}$ \\
\hline MR & 85 & $82.9 \%$ & $82.9 \%$ \\
\hline MS & 7 & $6.3 \%$ & $89.2 \%$ \\
\hline MR+MS & 5 & $4.5 \%$ & $93.7 \%$ \\
\hline MVP & 3 & $2.7 \%$ & $96.4 \%$ \\
\hline MVP+MR & 4 & $3.6 \%$ & $100 \%$ \\
\hline $\begin{array}{l}\text { TOTAL PATIENTS } \\
\text { TOTAL LESIONS }\end{array}$ & 104 & 100.0 & \\
\hline
\end{tabular}

$P$ value $=0.001$

Intensity of the systolic and diastolic murmur was graded in to 6 grades, grade 2 murmur were found in $43(38.7 \%)$ cases, grade 3 in $51(45.9 \%)$, grade 4 in $14(12.6 \%)$ and grade 5 in $3(2.7 \%)$ cases. Valve lesions were inaudible by auscultation mostly they were mild or moderate and to a lesser extend severe on echocardiographic criteria for valve severity as shown in table 2.

Table 2: The number and percent of mitral valve disease which are inaudible during examination according to its severity.

\begin{tabular}{|c|c|c|c|c|c|c|c|}
\hline & \multicolumn{6}{|c|}{ ECHO MITRAL FINDINGS } & \\
\hline $\begin{array}{l}\text { ECHO } \\
\text { MITRAL } \\
\text { SEVERITY }\end{array}$ & $\begin{array}{l}\text { MR No } \\
\%\end{array}$ & $\begin{array}{l}\text { MS } \\
\text { No. \% }\end{array}$ & $\begin{array}{l}\text { MR+MS } \\
\text { No. } \%\end{array}$ & $\begin{array}{l}\text { MVP } \\
\text { No.\% }\end{array}$ & $\begin{array}{l}\text { MR+MVP } \\
\text { No.\% }\end{array}$ & $\begin{array}{l}\text { TOTAL } \\
\text { PAIENTS } \\
\%\end{array}$ & $\begin{array}{l}\text { TOTAL } \\
\text { LESIONNo. }\end{array}$ \\
\hline Mild & $\begin{array}{l}33.0 \\
74.5 \%\end{array}$ & $\begin{array}{l}5.0 \\
10.6 \%\end{array}$ & $\begin{array}{l}2.0 \\
4.3 \%\end{array}$ & $\begin{array}{l}2.0 \\
4.3 \%\end{array}$ & $\begin{array}{l}3.0 \\
6.4 \% \\
\end{array}$ & $\begin{array}{l}45.0 \\
100.0 \%\end{array}$ & \multirow{6}{*}{113} \\
\hline Moderate & $\begin{array}{l}30.0 \\
88.9 \%\end{array}$ & $\begin{array}{l}1.0 \\
2.8 \%\end{array}$ & $\begin{array}{l}1.0 \\
2.8 \%\end{array}$ & $\begin{array}{l}1.0 \\
2.8 \%\end{array}$ & $\begin{array}{l}1.0 \\
2.8 \%\end{array}$ & $\begin{array}{l}34.0 \\
100.0 \%\end{array}$ & \\
\hline Severe & $\begin{array}{l}3.0 \\
80.0 \% \\
\end{array}$ & $\begin{array}{l}1.0 \\
20.0 \% \\
\end{array}$ & $\begin{array}{l}0.0 \\
0.0 \%\end{array}$ & $\begin{array}{l}0.0 \\
0.0 \%\end{array}$ & $\begin{array}{l}0.0 \\
0.0 \%\end{array}$ & $\begin{array}{l}4.0 \\
100.0 \%\end{array}$ & \\
\hline $\begin{array}{l}\text { Mild- } \\
\text { Moderate }\end{array}$ & $\begin{array}{l}19.0 \\
95.5 \%\end{array}$ & $\begin{array}{l}0.0 \\
0.0 \%\end{array}$ & $\begin{array}{l}1.0 \\
4.5 \%\end{array}$ & $\begin{array}{l}0.0 \\
0.0 \%\end{array}$ & $\begin{array}{l}0.0 \\
0.0 \%\end{array}$ & $\begin{array}{l}20.0 \\
100.0 \%\end{array}$ & \\
\hline $\begin{array}{l}\text { Mild MR \& } \\
\text { Moderate MS }\end{array}$ & $\begin{array}{l}0.0 \\
0.0 \%\end{array}$ & $\begin{array}{l}0.0 \\
0.0 \%\end{array}$ & $\begin{array}{l}1.0 \\
100.0 \%\end{array}$ & $\begin{array}{l}0.0 \\
0.0 \%\end{array}$ & $\begin{array}{l}0.0 \\
0.0 \%\end{array}$ & $\begin{array}{l}1.0 \\
100.0 \%\end{array}$ & \\
\hline Total Patients & $\begin{array}{l}85.0 \\
82.9 \% \\
\end{array}$ & $\begin{array}{l}7.0 \\
6.3 \% \\
\end{array}$ & $\begin{array}{l}5.0 \\
4.5 \% \\
\end{array}$ & $\begin{array}{l}3.0 \\
2.7 \% \\
\end{array}$ & \begin{tabular}{|l|}
4.0 \\
$3.6 \%$ \\
\end{tabular} & $\begin{array}{l}104 \\
100.0 \%\end{array}$ & \\
\hline P VALUE* & 0.001 & 0.001 & 0.62 & 0.02 & 0.226 & & \\
\hline
\end{tabular}

*Fisher's Exact Test

From all the results above, the conclusion is that clinical examinations by auscultation is of low sensitivity in the detection of murmur or other added sounds with high agreement rate in the diagnosis and follow up of patients with valvular heart disease as shown in table 3.

Table 3: The sensitivity, specificity, positive predictive value, negative predictive value, and agreement rate in cardiac mitral auscultation

\begin{tabular}{|l|l|l|l|}
\hline SENSITIVITY \% & SPECIFICITY \% & PV POSITIVE \% & PV NEGATIVE \% \\
\hline $48.4 \%$ & $100.0 \%$ & $100.0 \%$ & $86.9 \%$ \\
\hline
\end{tabular}

$\mathrm{P}$ value $<0.001 \ldots$. Agreement rate $=88.3 \%$

Significant numbers of lesions that were inaudible

typically ejection fraction of $25 \%$ to $54 \%$ (P were found in patients with low systolic function value $=0.001)$ as shown in table 4 . 
Table 4: The correlation between cardiac mitral auscultation and systolic function during echocardiography examination

\begin{tabular}{|l|l|l|}
\hline $\begin{array}{l}\text { ECHO SYSTOLIC } \\
\text { FUNCTION (EF \%) }\end{array}$ & $\begin{array}{l}\text { Positive } \\
\text { auscultation } \\
\text { No. }(\%)\end{array}$ & $\begin{array}{l}\text { Negative } \\
\text { auscultation } \\
\text { No. }(\%)\end{array}$ \\
\hline $25-35$ & $4(3.6 \%)$ & $11(10.57 \%)$ \\
\hline $36-45$ & $12(10.8 \%)$ & $19(18.3 \%)$ \\
\hline $46-54$ & $22(19.8 \%)$ & $36(34.6 \%)$ \\
\hline $55-70$ & $73(65.77 \%)$ & $38(36.5 \%)$ \\
\hline TOTAL PATIENTS & $111(100.0 \%)$ & $104(100.0 \%)$ \\
\hline
\end{tabular}

Fisher's Exact Test $\mathrm{P}$ value $=0.001$

On cardiac aortic auscultation there were 82 cases of aortic regurgitation, 36 cases of aortic stenosis, and 4 cases of mixed aortic regurgitation and stenosis ( 86 AR and 40 AS lesions with total 126 lesions). Among these patients, 24 AR lesions were associated with MR, 8 AR lesions were associated with MS, 2 AR lesions were associated with MVP and 6 of AS lesions were associated with MR. Bicuspid aortic valve was found in 18 valve lesions, in 11 lesions they were associated with AR and in 7 lesions they were associated with AS. Among the 82 AR lesions, in only 34 lesions the murmur was detected on auscultation, among the 36 lesions of AS the murmur was detected in 33 lesions and only in 3 lesions were not detected clinically, and among the 4 lesions of mixed AS\&AR in 2 lesions the murmur was detected. Thirty eight of 53 aortic valve lesions in which they were normal on auscultation they were mild on echocardiography examination, whereas the remaining 15 lesions were moderate to severe ( $\mathrm{p}$ value $=0.001)$, as shown in table 5 .

Table 5: The frequency of different types of aortic valve diseases which are audible and inaudible on auscultation and its severity

\begin{tabular}{|c|c|c|c|c|c|c|c|c|}
\hline $\begin{array}{l}\text { Aortic } \\
\text { auscultation }\end{array}$ & $\begin{array}{l}\text { Mild } \\
\text { No. } \\
\%\end{array}$ & $\begin{array}{l}\text { Moderate } \\
\text { No. } \\
\%\end{array}$ & $\begin{array}{l}\text { Severe } \\
\text { No. } \\
\%\end{array}$ & $\begin{array}{l}\text { Mild- } \\
\text { moderate } \\
\text { AR } \\
\text { No. } \\
\%\end{array}$ & $\begin{array}{l}\text { Moderate- } \\
\text { severe AR } \\
\text { No. } \\
\%\end{array}$ & $\begin{array}{l}\text { Mild } \\
\text { AR\&severe } \\
\text { AS } \\
\text { No. } \\
\%\end{array}$ & $\begin{array}{l}\text { Moderate } \\
\text { AR \& } \\
\text { severe AS } \\
\text { No. } \\
\%\end{array}$ & $\begin{array}{l}\text { Total } \\
\text { Patients } \\
\text { No. } \\
\%\end{array}$ \\
\hline Normal & $\begin{array}{l}38 \\
31.14 \%\end{array}$ & $\begin{array}{l}8 \\
6.55 \%\end{array}$ & $\begin{array}{l}0 \\
0.0 \%\end{array}$ & $\begin{array}{l}3 \\
2.45 \%\end{array}$ & $\begin{array}{l}1 \\
0.81 \%\end{array}$ & $\begin{array}{l}2 \\
1.63 \%\end{array}$ & $\begin{array}{l}1 \\
0.81 \%\end{array}$ & $\begin{array}{l}53 \\
43.44 \%\end{array}$ \\
\hline AR & $\begin{array}{l}13 \\
10.65 \%\end{array}$ & $\begin{array}{l}12 \\
9.83 \%\end{array}$ & $\begin{array}{l}3 \\
2.45 \%\end{array}$ & $\begin{array}{l}6 \\
4.91 \%\end{array}$ & $\begin{array}{l}0 \\
0.0 \%\end{array}$ & $\begin{array}{l}0 \\
0.0 \%\end{array}$ & $\begin{array}{l}0 \\
0.0 \%\end{array}$ & $\begin{array}{l}34 \\
27.86 \%\end{array}$ \\
\hline AS & $\begin{array}{l}12 \\
9.83 \%\end{array}$ & $\begin{array}{l}15 \\
12.29 \%\end{array}$ & $\begin{array}{l}5 \\
4.09 \%\end{array}$ & $\begin{array}{l}0 \\
0.0 \%\end{array}$ & $\begin{array}{l}0 \\
0.0 \%\end{array}$ & $\begin{array}{l}1 \\
0.81 \%\end{array}$ & $\begin{array}{l}0 \\
0.0 \%\end{array}$ & $\begin{array}{l}33 \\
27.04 \%\end{array}$ \\
\hline $\mathrm{AR}+\mathrm{AS}$ & $\begin{array}{l}0 \\
0.0 \%\end{array}$ & $\begin{array}{l}1 \\
0.81 \%\end{array}$ & $\begin{array}{l}0 \\
0.0 \%\end{array}$ & $\begin{array}{l}0 \\
0.0 \%\end{array}$ & $\begin{array}{l}0 \\
0.0 \%\end{array}$ & $\begin{array}{l}0 \\
0.0 \%\end{array}$ & $\begin{array}{l}1 \\
0.81 \%\end{array}$ & $\begin{array}{l}2 \\
1.63 \%\end{array}$ \\
\hline Total & $\begin{array}{l}63 \\
51.63 \%\end{array}$ & $\begin{array}{l}36 \\
29.5 \%\end{array}$ & $\begin{array}{l}8 \\
6.55 \%\end{array}$ & $\begin{array}{l}9 \\
7.37 \%\end{array}$ & $\begin{array}{l}1 \\
0.81 \%\end{array}$ & $\begin{array}{l}3 \\
2.45 \%\end{array}$ & $\begin{array}{l}2 \\
1.63 \%\end{array}$ & $\begin{array}{l}122 \\
100.0 \%\end{array}$ \\
\hline
\end{tabular}

Fisher's Exact Test $\mathrm{P}$ value $=0.001$

Auscultation is of low sensitivity $(55.7 \%)$ in detecting aortic valve lesion with high agreement rate $(94.3 \%)$ and $\mathrm{P}$ value $=0.001$ as shown in table 6 . 
Table 6: The sensitivity, specificity, positive predictive value and negative predictive value in cardiac aortic auscultation

\begin{tabular}{|l|l|l|l|}
\hline SENSITIVITY \% & SPECIFICITY \% & PV POSITIVE \% & PV NEGATIVE \% \\
\hline $55.7 \%$ & $100.0 \%$ & $100.0 \%$ & $93.9 \%$ \\
\hline
\end{tabular}

$\mathrm{P}$ value $<0.001 \ldots$. Agreement rate $=94.3 \%$

From the 53 aortic valve lesions in which they were not audible by auscultation, in 24 lesions the

fraction between $25 \%$ and $54 \%$ (LV dysfunction) patients had low LV systolic with their ejection

$\mathrm{p}$ value $=0.001$ as shown in table 7

Table 7: The correlation between Cardiac aortic auscultation and Echo systolic function

\begin{tabular}{|l|l|l|}
\hline $\begin{array}{l}\text { Echo systolic function } \\
(\mathrm{EF} \%)\end{array}$ & $\begin{array}{l}\text { Positive } \\
\text { auscultation } \\
(\%)\end{array}$ & $\begin{array}{l}\text { Negative } \\
\text { auscultation } \\
\text { No. }(\%)\end{array}$ \\
\hline $25-35$ & $2(2.9 \%)$ & $1(1.9 \%)$ \\
\hline $36-45$ & $3(4.4 \%)$ & $2(3.8 \%)$ \\
\hline $46-54$ & $15(21.7 \%)$ & $21(39.6 \%)$ \\
\hline $55-70$ & $49(71.0 \%)$ & $29(54.7 \%)$ \\
\hline TOTAL & $69(100.0 \%)$ & $53(100.0 \%)$ \\
\hline
\end{tabular}

Fisher's Exact Test $\mathrm{P}$ value $=0.001$

\section{Discussion}

In this study we were concentrated on providing detailed information about clinical auscultation in clinical practice with its sensitivity if compared to echocardiography examination. Unfortunately there was limited similar study for comparison. Among 300 patients we were found 215 patients having 248 mitral valve lesions including MR, MS, and MVP either isolated lesion or in combination. MR was the most common lesion recorded singly or in combination and was noted in 189 out of 215 cases diagnosed by echo whether isolated or in association with other valve disease and 95 out of 189 MR lesions were diagnosed clinically by auscultation. This is in agreement with Ashwin Reddy et al study in which MR is the most common lesion detected, 42 out of 50 cases $(84 \%)$, but unlike the study in the frequency of MS which is the second most common in 29 out of 50 cases $(58 \%)$, while in present study it was the fourth common lesion ${ }^{14}$. In current study AR was the second most common valve lesion noted but in Ashwin Reddy et al was the third common in frequency 15 out of 50 cases (30\%). From total 189 MR either pure or in combination were diagnosed by echocardiography in $94 \mathrm{MR}$ no murmur was detected, with $\mathrm{p}$ value= 0.001. This was in concordance with Ashwin Reddy et al study in which the P value was 0.039 . Form total 36 cases of MS including 16 cases in combination with MR, in 7 cases of pure MS no murmur was detected clinically and in 5 combined MS\&MR there were no findings clinically $p$ value $=0.001$. This is unlike Ashwin Reddy et al in which MS was not found clinically in 4 out of 29 cases with $P$ value of 0.625 . In present study from total 82 cases of AR only in 34 cases the murmur was audible, this was inconsistent with Ashwin Reddy et al. It was in agreement with this study in the incidence of combined aortic and mitral valve diseases which were found in $27 \%$. This study was in agreement with Ashwin Reddy et al study in that there was significant difference between clinical examination and echocardiography ( $\mathrm{p}$ value $<0.05$ ) determined by McNemar's test, and by sensitivity, specificity and predictive value. Ashwin Reddy et al study was not found any patient with AS because the study age group was mostly pediatric age between 5-16 years old. All the differences between our study and Ashwin et al study is that they had smaller sample size, they were selected pediatric age group and 
because the auscultation was done by medical students. In Jaffe et al study which was included 75 patients with total 146 valve lesions, in 32 cases of AS lesion only in 6 cases the murmur was not audible or inconclusive clinical examination which is higher in compare to present study, in 40 cases of AR only in 8 cases the murmur was not audible which was much lower than the result of this study, in 29 cases of MS only in 9 cases the murmur was not audible it was near the result of present study, and in 45 cases of MR only in 5 cases the murmur was not audible which is much lower than the result in our study ${ }^{15}$. The differences between Jaffe et al study and this study was because of smaller sample size in Jaffe et al study and because of the basis for selection of patients studied is different. In a survey done to estimate the proportion of murmur detection by clinical auscultation among physicians and cardiologists in Erbil city, the result was surprising. From total 50 physicians were asked "What's the percentage of murmur you can auscultate in aortic and mitral valve diseases? “ the answer was that most of the physicians was though that diastolic murmurs were difficult to be auscultate, and to a lesser extent systolic murmurs. Most (80\%) were though that early diastolic and mid diastolic murmurs are difficult to examine, and most of them were though that systolic murmur of MR especially holosystolic is easily audible. In the current study there was a significant association between inaudible valve lesions from mitral and aortic auscultation with low LV systolic function ( $\mathrm{P}$ value $=0.001)$ this is because in patients with valvular lesion even if it is severe caused by LV dilation the systolic murmur may be barely audible or even absent because of low stroke volume, a condition referred to as silent valve disease ${ }^{16}$. So our study results were concluding that auscultation is not sensitive in both mitral and aortic auscultation, $48.4 \%$ and $55.7 \%$ respectively.

\section{Acknowledgment}

The authors report no conflict of interest.

\section{References}

1. Catherine M, Otto and Robert O, Bonow. Valvular heart disease. In: Douglas L. Mann, Douglas P. Zipes, Peter Libby, editors. Braunwald's Heart Disease. Philadelphia: Elsevier Saunders; 2015; p. 1690

2. Dare A, et al. Evaluation of surgically excised mitral valves: Revised recommendations, based on changing operative procedures in the 1990s.Hum Pathol 1993; 24:1286

3. Rosenhek R, Binder T, Porenta G. Predictors of outcome in severe, asymptomatic aortic stenosis. N Engl J Med. 2000; 343:611-17.

4. Jeffrey $\mathrm{R}$ Bender, M.D. Heart Valve Disease.www.

http://doc.med.yale.edu/heartbk/13

5. Tzemos N, Therrien J, Yip J, et al: Outcomes in adults with bicuspid aortic valves. JAMA 300:1317, 2008.

6. Nihoyannopoulos P, Fox K, Fraser A, Pinto F. EAE laboratory standards and accreditation. Eur J Echocardiogr. 2007; 8: 80-7.

7. Fink JC, Schmid CH, Selker HP. A decision aid for referring patients with systolic murmurs for echocardiography. J Gen Intern Med.1994; 9:479-84. of echocardiography in clinical trials. J Am Soc Echocardiogr. 2004;17:1086-1119.

8. Michael A. Chizner. Cardiac Auscultation: Rediscovering the Lost Art. Curr Probl Cardiol, 2008;33:326-40

9. Bickley, LS. Bates' Guide to Physical Examination and History Taking. 7th edition, Philadelphia; Lippincott 1999.

10. Chatterjee K. Auscultation of cardiac murmurs. In: Up To Date, Rose, BD (Ed), Up To Date, Waltham, MA, 2006.

11. Michael A. Chizner, MD. Cardiac Auscultation: Rediscovering the Lost Art. Curr Probl Cardiol. 2008; 33:326-408.

12. Robert O Bonow, Blase Carabello, Antonio C. de Leon, et al. Guidelines for 
the Management of Patients With Valvular Heart Disease: Executive Summary A Report of the American College of Cardiology/American Heart Association Task Force on Practice Guidelines (Committee on Management of Patients With Valvular Heart Disease), 2014. Circulation, http www.circ.ahajournals.org

13. Catherine M, Otto and Robert O, Bonow.Valvular heart disease.In: Douglas L. Mann, Douglas P. Zipes, Peter Libby, editors. Braunwald's Heart Disease. Philadelphia: Elsevier Saunders; 2015; p. 1708

14. Ashwin Reddy, Lt Col Sk Jatana, Col MNG Nair. Clinical Evaluation Versus Echocardiography in the Assessment of Rheumatic Heart Disease. MJAFI.2004; 60: 255-258

15. W M Jaffe, A. H Roche, H A Coverdale, H. F McAlister, J. A Ormiston and E. R Greene. Clinical Evaluation versus Doppler Echocardiography in the Quantitative Assessment of Valvular Heart Disease. Circulation. 1988; 78:267-275

16. Catherine M, Otto and Robert O, Bonow. Valvular heart disease. In: Douglas L. Mann, Douglas P. Zipes, Peter Libby,editors. Braunwald's Heart Disease. Philadelphia: Elsevier Saunders; 2015; 1473-1484. 